\title{
SIMULATION OF AN INTERLOCKING HYDRAULIC DIRECT-DRIVE SYSTEM FOR A BIPED WALKING ROBOT
}

\author{
Juri Shimizu*, Takuya Otani, Kenji Hashimoto, Atsuo Takanishi \\ Waseda University and Hitachi, Ltd./\#41-304, 17 Kikui-cho 162-0044, Shinjuku-ku, Tokyo, JAPAN \\ * Corresponding author: Tel.: +81 33203 4394; E-mail address: juri-shimizu1112@asagi.waseda.jp
}

\begin{abstract}
Biped robots with serial links driven by an electric motor experience problems because the motor and transmission are installed in each joint, causing the legs to become very heavy. Previous solutions involved robots using servo valves, a type of highly responsive proportional valve. However, high supply pressure is necessary to realize high responsiveness and the resulting energy losses are large. To address this problem, we proposed a hydraulic direct-drive system in which the pump controls the cylinder meter-in flow, while a proportional valve controls the meter-out flow. Furthermore, our hydraulic interlocking drive system connects two hydraulic direct-drive systems for biped humanoid robots and concentrates the pump output on one side cylinder. The meter-in flow rate of the other side cylinder is controlled by the meter-out flow rate of the cylinder on which the pump is concentrated. A comparison of the walking simulation performance with that of the conventional independent system shows that our proposed system reduces the motor output power by $24.3 \%$. These results prove the feasibility of constructing a two-legged robot without having to incorporate highly responsive servo valves.
\end{abstract}

Keywords: Hydraulics, Bipedal locomotion, Humanoid robot, Flow-based control

\section{INTRODUCTION}

It is important to conduct safe quantitative assessments of the products people use. The main method currently in use for this purpose is user rating. However, this approach provides qualitative results only. Thus, our research group proposes using a biped humanoid robot instead of humans to evaluate products. Our developed Robot WABIAN-2R (WAseda BIpedal humANoid-No. 2 Refined) can walk with its knees extended by implementing a pelvic mechanism [1]. Figure 1 shows our biped humanoid robot. In recent years, we have developed robots that can evaluate various products. They run as well as walk. To run, a robot requires a high-power actuator. However, it is difficult to implement high-power electric motors because of the size limitations of robots. To solve this problem, we proposed a method to generate a large torque via pelvic vibration and leg elasticity $[2,3]$.

To increase the output of electric motors, Urata et al. developed a technology that improves continuous output torque with a liquid cooling system [4]. Other robots have two or three motors on the drive shaft [5-7]. These approaches have led to the development of high-speed, hightorque, and highly mobile joints for humanoid legs. However, these conventional methods require that the shafts of the motor be directly connected by mechanical transmission. It is difficult to place the equipment to have the same weight distribution as in the case of a human. However, the equipment layout can be improved by using a hydraulic system.

The hydraulic system can realize a robot of the same size as a human. For example, Boston Dynamics developed ATLAS [8]. Hyon et al. developed a hydraulic humanoid robot called $\mathrm{TaeMu}$ [9], which has the same leg link ratio and weight distribution as humans. This robot can directly control the torque of each joint by adjusting the actuator pressure by using a servo valve. However, for our intended use, we need to reproduce a predetermined motion pattern in order to evaluate a product. This requires a system that can directly control the joint angle. The displacement control system is flow-based and can directly control the actuator stroke with 
the pump discharge flow $[10,11]$. Kaminaga et al.'s Electric Hydrostatic Actuator (EHA) is an example of such a system being applied to a robot [12]. However, since EHA uses a through rod cylinder, the output is lower than that of a single rod cylinder, making it difficult to install because of rod moving space.

Previously, we proposed a Hydraulic DirectDrive system (HDD) based on a displacement control system that uses a single rod cylinder for a biped humanoid robot [13]. In the HDD system, the meter-in flow rate of a single rod cylinder is controlled by the pump discharge flow rate, and the cylinder meter-out flow rate is controlled by a proportional valve. The proposed system showed excellent energy transfer efficiency and excellent speed tracking capability in the evaluation bench system. Furthermore, the results showed that biped walking can be realized by an HDD system using a hydraulic-mechanical cosimulation model [14].

However, the HDD is implemented independently at each joint. This resulted in a problem in that the output of each pump increased to satisfy the required maximum output of each joint. In order to solve this problem, an interlocking circuit that focuses on the symmetry structure of the biped mechanism and the symmetry of motion was proposed [15]. It was shown that the proposed system reduced the maximum output of the motor by $27.3 \%$ in the evaluation bench device that simulated the load during walking compared to the case without the system.

In this study, a HDD with an interlocking circuit is applied to a biped humanoid robot to check whether walking can be realized. The results of the performance comparison without application of the interlock circuit verify the effectiveness of the proposed system.

The remainder of this paper is organized as follows: Section 2 introduces the design of the interlock circuit and its theoretical model for the HDD system. Section 3 describes the experimental setup, procedures, and results. Section 4 discusses future prospects and concludes the paper.

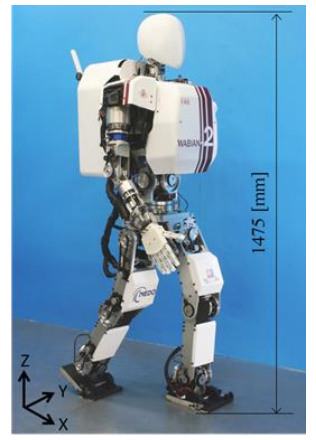

Figure 1: Example of our developed biped robot (WABIAN-2R)

\section{CONSTRUCTION OF INTERLOCKING CIRCUIT FOR HYDRAULIC DIRECT. DRIVE SYSTEM}

This section describes the configuration and control method of the proposed interlocking circuit for the HDD system. Section 2.1 presents the proposed interlock design, and Section 2.2 establishes the proposed control method.

\subsection{Hydraulic Circuit}

In a previous work, we proposed a hydraulic interlocking drive system that interlocks two joints [15]. The hydraulic circuit for our proposed system is shown in Figure 2. The pump units and cylinders are connected in a closed circuit. Valves $1 \mathrm{a}, 1 \mathrm{~b}, 2 \mathrm{a}$, and $2 \mathrm{~b}$ are installed on the flow pass between the pump and cylinder. We use Takako's pump unit [16] for our test rig. An axial piston pump, two relief valves to protect the pump, and a special check valve are included in the unit. The special check valve has two normal check valves, which are connected to each other by a rod. Therefore, this special check valve connects the lower pressure side of the pump port to the tank. The pump unit has two ports and can discharge from both ports. Port A of the pump is connected to the cap side of the cylinder, and Port B is connected to the rod side. Proportional solenoid valves are used for valves $1 \mathrm{a}, 1 \mathrm{~b}, 2 \mathrm{a}$, and $2 \mathrm{~b}$. Four variable relief valves are installed to adjust the relief pressure in order to protect the circuit.

Valve 3a connects Port A of Pump Unit 1 and Port B of Pump Unit 2, and Port B of Pump Unit 1 and Port A of Pump Unit 2. The rod sides of 


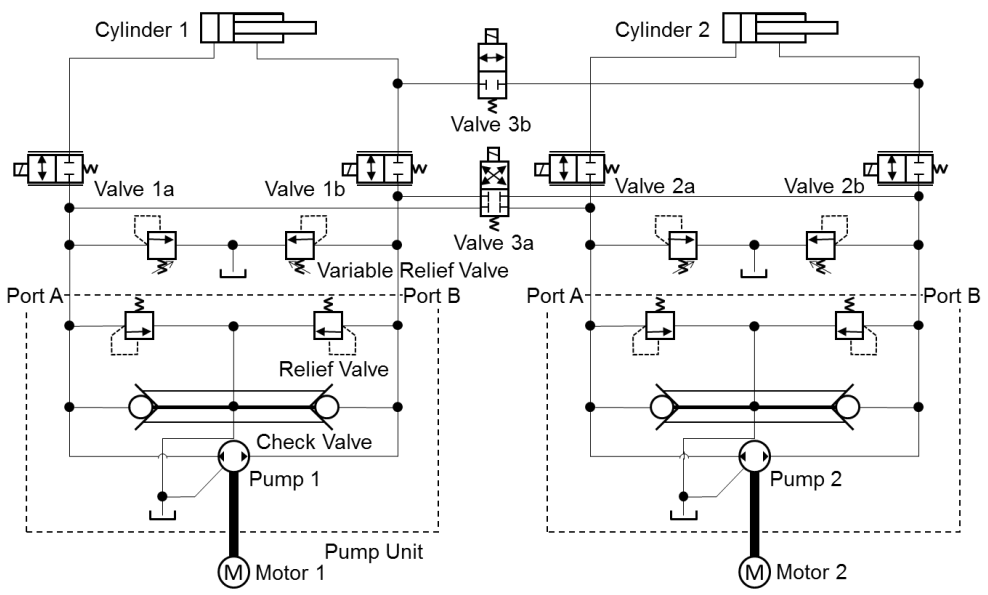

Figure 2: Hydraulic interlocking drive circuit

Cylinders 1 and 2 are connected through Valve $3 b$. Valves $3 a$ and $3 b$ are solenoid on-off valves. There are two drive modes in the circuit in Figure 2. The first drive mode is an independent drive mode. In this mode, it operates as the proposed single HDD system [13]. Pump 1 controls the meter-in flow of Cylinder 1, and Valve 1b or 1a controls its meter-out flow. The meter-in flow and meter-out flow of Cylinder 2 are also controlled by Pump 2 and Valve $2 \mathrm{a}$ or $2 \mathrm{~b}$. The effects of this mode are demonstrated in our previous work $[13,14]$.

The second drive mode is an interlocking drive mode. An example of this mode is shown in Figure 3. In this drive mode, Valves $3 a$ and $3 b$ are open. An interlocking flow pass is formed by opening Valve $3 \mathrm{~b}$. The meter-in flow of Cylinder 1 can be decided by the combined flow of Pumps 1 and 2. The meter-out flow of Cylinder 1 becomes the meter-in flow of Cylinder 2. Valve $2 \mathrm{a}$ can control the meter-out flow of Cylinder 2.

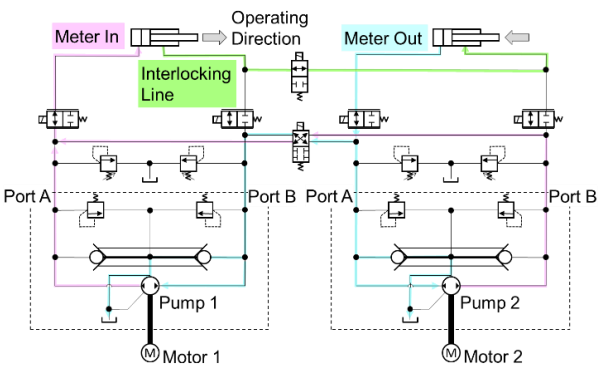

Figure 3: Interlocking drive mode

\subsection{Control Method}

The control methods of the independent and interlocking drive modes proposed in the previous research $[13,15]$ are described here.

In the first drive mode, the demand meter-in flow of Cylinder 1 (2), $Q_{d C y l 1(2) i n}$, is controlled by the flow delivered by Pump 1 (2). In an HDD system, the flow rate delivered by Pump 1 can be controlled by rotational speed $\omega_{1}$. The demand meter-out flow of Cylinder $1, Q_{d c y l 1 ~ o u t}$, is controlled by the opening area of Valve $1 \mathrm{a}$ or $1 \mathrm{~b}$ (2a or $2 \mathrm{~b}$ ), $A_{d V 1 a}$ or $A_{d V 1 b}$ [13]. For $Q_{d C y l 1 \text { in }}$, the demand rotational speed of Pump 1, $\omega_{\text {dPump } 1}$, is given by

$\omega_{d P u m p 1}=\frac{Q_{d c y l 1 \text { in }}}{D_{P 1} \eta_{p v}}$,

where $D_{P 1}$ is the displacement of Pump 1, and $\eta_{p 1 v}$ is its volumetric efficiency. $A_{d V 1 a}$ is defined as

$A_{d V 1 a}=\frac{Q_{d C y l 1 \text { out }}}{C_{d}} \sqrt{\frac{\rho}{2\left(P_{V 1 a \text { in }}-P_{V 1 a} \text { out }\right)}}$,

where $C_{d}$ is the flow coefficient, $P_{V 1 a}$ in and $P_{V 1 a}$ out are the pressures at the input port and output port of Valve 1a, respectively, and $\rho$ is the density of the fluid. $P_{V 1 a}$ out is almost the same as the tank pressure (zero). $P_{V 1 a}$ in is almost the same as the cap pressure of Cylinder 1 in the cylinder stroke drive.

In the simplest pattern in the second drive mode, the velocities of the two cylinders are the same and the operation directions are opposite, as seen in Figure 3. In such a pattern, $Q_{d c y l 1}$ out and the demand meter-in flow of Cylinder 2, 
$Q_{d c y l 2 \text { in }}$, are equal. $Q_{d c y l 1 \text { in }}$ is decided by the flows delivered by Pumps 1 and 2. These flows are controlled by the rotational speeds of Pumps 1 and $2, \omega_{d P u m p} 1$ and $\omega_{d P u m p}$, respectively, which are expressed as follows:

$\omega_{d P u m p 1}=\beta \frac{Q_{d C y l 1 \text { in }}}{D_{P 1} \eta_{p 1 v}}$,

$\omega_{d P u m p 2}=(1-\beta) \frac{Q_{d c y l 1 \text { in }}}{D_{P 2} \eta_{p 2 v}}$,

where $\beta$ is the flow rate ratio delivered by the pump. $\beta$ is adjusted to compensate for the pressure loss in Valve 3a and make the output of the two pumps uniform. The meter-out flow of Cylinder 2 is controlled by the demand opening area of Valve 2a, $A_{d V 2 a}$, based on (2).

In actual patterns such as walking or running, the patterns of actuators are more complicated, and the velocities of the two cylinders are different. Therefore, $Q_{d c y l 1 \text { out }}$ and $Q_{d c y l 2}$ in are different. For such a situation, we proposed flow rate compensation to control $Q_{d c y l 2}$ in. The compensation flow, $Q_{\text {Comp }}$, is given by

$$
Q_{\text {comp }}=Q_{d C y l 1 \text { out }}-Q_{d C y l 2 \text { in }} \text {. }
$$

There are two modes for $Q_{\text {Comp }}$. In the first mode, $Q_{\text {Comp }}$ is positive, and extra flow exists in the interlocking line. This flow must be discharged to the tank. Valve $1 \mathrm{~b}$ can be used for the discharge, and its demand flow rate, $Q_{d V 1 b}$, is given by
$Q_{d V 1 b}=\left\{\begin{array}{ll}Q_{\text {Comp }} & \left(Q_{\text {Comp }}>0\right) \\ 0 & \left(Q_{\text {Comp }}<0\right)\end{array}\right.$.

In the second mode, $Q_{\text {Comp }}$ is negative. In this mode, in order to rectify the flow rate deficiency, it is necessary to increase the flow rate from the outside to the interlocking line. Valve $2 \mathrm{~b}$ and Pump 2 can be used to obtain the required flow rate. The demand flow rate of Valve $2 \mathrm{~b}, Q_{d V 2 b}$, is given by

$Q_{d V 2 b}=\left\{\begin{array}{ll}0 & \left(Q_{\text {Comp }}>0\right) \\ -Q_{\text {Comp }} & \left(Q_{\text {Comp }}<0\right)\end{array}\right.$.

The delivery flow rate of Pump 2 must also be increased to the delivery demand flow rate of Valve $2 \mathrm{~b}, Q_{d V 2 b}$. Therefore, the demand pump rotational speed, $\omega_{d P u m p}$, is determined using (4) and (7).

$\omega_{d P u m p 2}=\frac{(1-\beta) Q_{d C y l 1 \text { in }}+Q_{d V 2 b}}{D_{P 2} \eta_{p 2 v}}$

When $Q_{d V 2 b}$ is required, in order to maintain the ratio of $Q_{C y l 1 \text { in }}$ and $Q_{d V 2 b}$, it is necessary to control the opening area of Valve 1a based on (2). When Valve $2 b$ is not used, the opening area of Valve 1a is set at the maximum in order to suppress energy loss.

The block diagram of the proposed system is shown Figure 4.

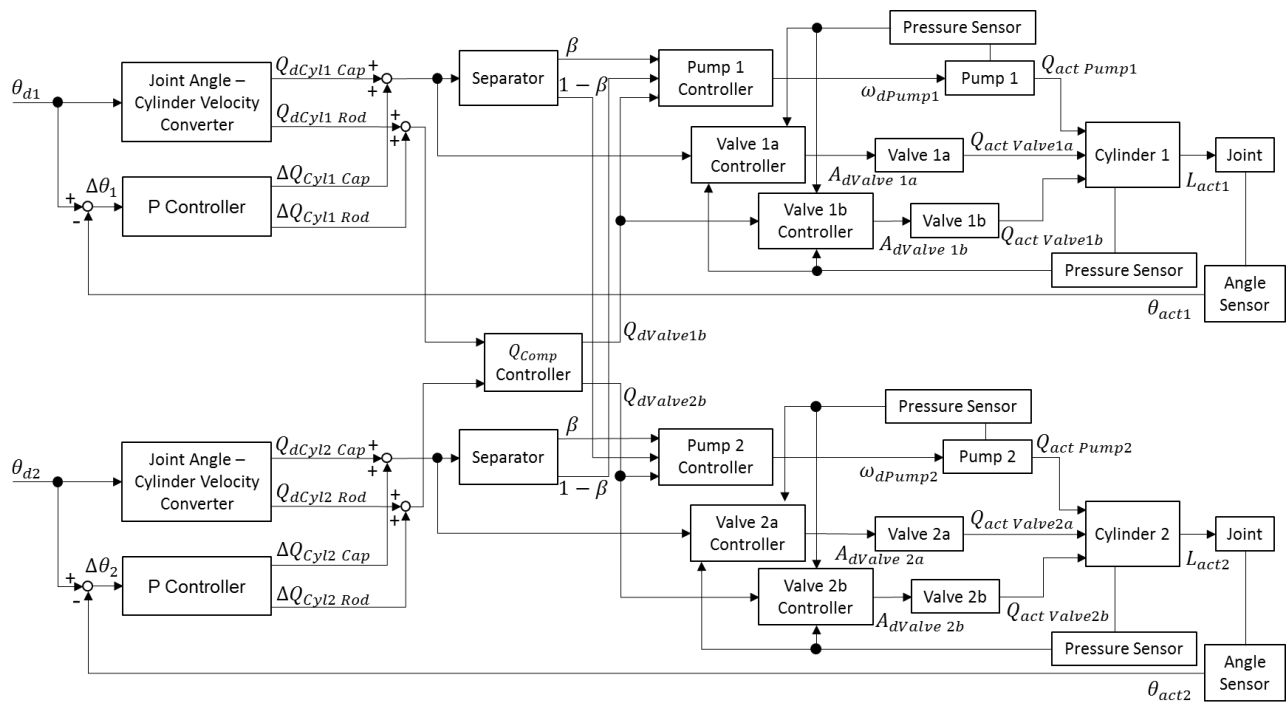

Figure 4: Block diagram of interlocking drive mode 


\subsection{Evaluation}

The energy-saving performance of the proposed interlocking mode was evaluated experimentally. The mechanical hydraulic co-simulation model was used to confirm whether the maximum output of the two pump drive motors can be reduced by the walking pattern. The maximum output of the motor during walking when the HDD was used independently was compared with the situation when the interlocking drive mode was applied. The details are presented in Section III.

\section{EXPERIMENTS}

The walking simulations for the proposed interlocking circuit are examined, and the simulation setup and results are discussed in Sections 3.1 and 3.2, respectively. We used the physical modeling tool LMS Imagine.Lab Amesim $^{\mathrm{TM}}$ (Siemens K.K.) to evaluate the interlocking circuit.

\subsection{Experimental setup}

We developed the bench test equipment to evaluate the proposed system. The hydraulic circuit of the bench is shown in Fig. 3.

To evaluate the proposed interlocking drive system, we developed a mechanical hydraulic cosimulation model of a biped humanoid robot. The construction of the mechanical model was based on the link mechanism and mass arrangement of our biped humanoid robot WABIAN-2R [1]. The proposed interlocking drive system served as the hydraulic model. Our proposed hydraulic system was applied to the hip pitch joints. The hip joints require high torque and joint density, and mounting the drive system poses difficulties because of space limitations. The other joints in the model used the conventional electrical motor and mechanical transmission system. The hydraulic and mechanical co-simulation models are shown in Figures 5 and 6, respectively. The hydraulic model is based on the HDD system constructed in the previous research, and reflects the pump efficiency and responsiveness of the valves and motors based on experiments. The corresponding parameters are listed in Table 1. Figure 6 shows the link mechanism of the hip joint. The four-bar linkage mechanism was employed to secure a wide joint drive range. The parameters of the link mechanism are listed in Table 2.

Table 1: Hydraulic circuit model parameters

\begin{tabular}{|c|c|c|}
\hline \multicolumn{2}{|c|}{ Pump displacement [cc/rev] } & 1.6 \\
\hline \multicolumn{2}{|c|}{ Pump relief pressure $[\mathrm{MPa}]$} & 21.0 \\
\hline \multicolumn{2}{|c|}{ Cylinder stroke [mm] } & 132.0 \\
\hline \multicolumn{2}{|c|}{ Cylinder piston diameter [mm] } & 25.0 \\
\hline \multicolumn{2}{|c|}{ Cylinder rod diameter [mm] } & 16.0 \\
\hline \multicolumn{2}{|c|}{ Variable relief valve set pressure $[\mathrm{MPa}]$} & 4.0 \\
\hline \multicolumn{2}{|c|}{ Hose inner diameter [mm] } & 6.4 \\
\hline \multirow{4}{*}{$\begin{array}{l}\text { Hose length } \\
{[\mathrm{mm}]}\end{array}$} & $\begin{array}{l}\text { Pump to Valves } 1 \mathrm{a}, 1 \mathrm{~b}, 2 \mathrm{a} \text {, and } \\
2 \mathrm{~b}\end{array}$ & 1000.0 \\
\hline & Pump to Valve $3 a$ & 300.0 \\
\hline & $\begin{array}{l}\text { Valves } 1 \mathrm{a}, 1 \mathrm{~b}, 2 \mathrm{a} \text {, and } 2 \mathrm{~b} \text { to } \\
\text { Cylinder } 1,2\end{array}$ & 2000.0 \\
\hline & Valves $3 \mathrm{~b}$ to Cylinder 1,2 & 300.0 \\
\hline \multicolumn{2}{|c|}{$\begin{array}{l}\text { Valves 1a, 1b, 2a, and 2b: Nominal flow rate } \\
{[\mathrm{L} / \mathrm{min} /(\mathrm{MPa})]}\end{array}$} & 5.0 \\
\hline \multicolumn{2}{|c|}{$\begin{array}{l}\text { Valves 1a, 1b, 2a, and 2b: } \\
\text { Valve Natural Frequency }[\mathrm{Hz}]\end{array}$} & 20.0 \\
\hline \multicolumn{2}{|c|}{$\begin{array}{l}\text { Valves } 3 \mathrm{a} \text { and } 3 \mathrm{~b} \text { : Nominal flow rate } \\
{[\mathrm{L} / \mathrm{min} /(\mathrm{MPa})]}\end{array}$} & 10.0 \\
\hline \multicolumn{2}{|c|}{$\begin{array}{l}\text { Valves 3a and 3b: Valve Natural Frequency } \\
{[\mathrm{Hz}]}\end{array}$} & 20.0 \\
\hline \multirow{2}{*}{\multicolumn{2}{|c|}{$\begin{array}{ll}\text { Oil kinematic } \\
\text { viscosity }\left[\mathrm{mm}^{2} / \mathrm{s}\right]\end{array} \frac{40[\operatorname{deg} \mathrm{C}]}{100[\operatorname{deg} \mathrm{C}]}$}} & 14.7 \\
\hline & & 3.7 \\
\hline \multicolumn{2}{|c|}{ Experimental oil temperature [deg C] } & 25.0 \\
\hline
\end{tabular}

Table 2: Parameters of the four-bar linkage mechanism (see also Figure 6)

\begin{tabular}{|c|c|}
\hline $\operatorname{Link}_{1}[\mathrm{~mm}]$ & 119.0 \\
\hline $\operatorname{Link}_{2}[\mathrm{~mm}]$ & 113.0 \\
\hline$X_{A}[\mathrm{~mm}]$ & 59.0 \\
\hline$X_{B}[\mathrm{~mm}]$ & 100.0 \\
\hline$Z_{A}[\mathrm{~mm}]$ & 34.0 \\
\hline$Z_{B}[\mathrm{~mm}]$ & 300.0 \\
\hline$Z_{c}[\mathrm{~mm}]$ & 57.0 \\
\hline Weight of Thigh $[\mathrm{kg}]$ & 4.2 \\
\hline Weight of cylinder $[\mathrm{kg}]$ & 2.0 \\
\hline Weight of $\operatorname{Link}_{1}[\mathrm{~kg}]$ & 0.6 \\
\hline Weight of Link $k_{2}[\mathrm{~kg}]$ & 0.4 \\
\hline
\end{tabular}




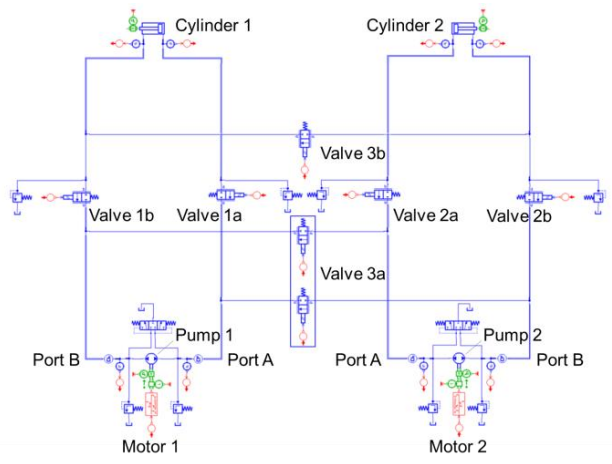

Figure 5: Hydraulic system of the co-simulation model

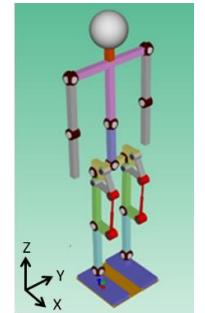

(a) Full mechanical model

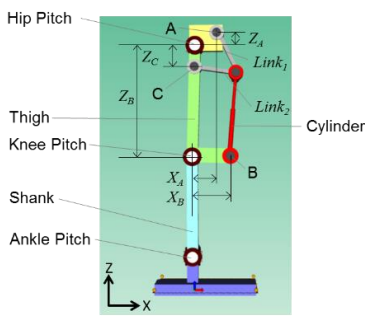

(b) Link parameters
Figure 6: Mechanical system of the co-simulation model

\subsection{Experimental procedure}

First, we used simulation experiments to confirm whether walking can be realized with the proposed interlocking system. Previous research suggests that the follow-up to the target trajectory deteriorates when the interlocking system is applied to the bench device [15]. It has been reported that when two pumps are joined to Cylinder 1, the follow-up performance of Cylinder 2 on the drive side worsens depending on the meter-out flow rate of Cylinder 1. In the interlock system, the pump output is concentrated on the cylinder that experiences the increased load. Therefore, when walking, the pump output is combined with the cylinder on the stance side when standing on one side. At this time, since the cylinder on the free leg side is controlled based on the meter-out flow rate of the cylinder on the standing side, there is a concern that the followability to the target trajectory may deteriorate. Even if the followability when the legs are swinging deteriorates, the trajectory is corrected before landing, and the simulation confirms whether walking can be realized.

In addition, using the results of the walking simulation, we evaluate the motor output reduction effect of the proposed interlocking system. In order to verify the effectiveness of the proposed system, we compare it with the results of the walking simulation of an HDD system reported in a previous study [14].

The motor size can be reduced by decreasing the motor output. The motor is selected based on the output required, the goal being to achieve the required maximum output for each axis. If the peak output of each motor is reduced by the interlocking system, a smaller motor can be selected, which contributes to weight reduction of the robot. This means that when a motor with the same output as the conventional one is installed, higher performance than before can be achieved. Therefore, the peak output of the motor during the walking motion is evaluated in the comparative experiment.

The walking pattern of the simulation experiment was generated using the offline pattern generation method proposed by our research group. The group has a proven track record of walking with WABIAN-2R [1], the basis of the mechanism model. In this study, we applied the eight-step walking pattern with the knee extended, which is a feature of WABIAN$2 \mathrm{R}$. The interlocking system was applied in single-stance phases from the second step to the seventh step.

\subsection{Experimental results}

The results of the walking simulations are shown in Figures 7 and 8. Figure 7 shows the walking motion of the biped humanoid robot model with the proposed interlocking drive system, and Figure 8 shows the position responses of the right and left joints during walking. These results show that the proposed interlocking drive system can follow the demand trajectory under the walking motion load, thereby realizing biped walking.

Figure 9 shows the power of Motor 1 without the interlocking drive system. As shown in Figure 9, when the joint angle of the right link increases, such as at 2.7-3.4 s, the side with the right link reproduces the single stance phase. In this section, reflection force from ground is added to the cylinder on the right (Cylinder 1). Thus, the output of Motor 1 increases, as shown in 
Figure 9. The maximum power in the independent drive mode is $351.6 \mathrm{~W}$.

Figure 10 shows the power of Motor 1 when the interlocking drive mode is applied. This mode is applied during the single stance phase. As shown in Figure 10, the peak power of Motor 1 can be reduced to $266.2 \mathrm{~W}$ by applying the interlocking drive mode when the single stance on the right side is reproduced. Therefore, the maximum motor power can be reduced by $24.3 \%$ with the proposed interlocking drive system.



Figure 7: Walking motion of the co-simulation model

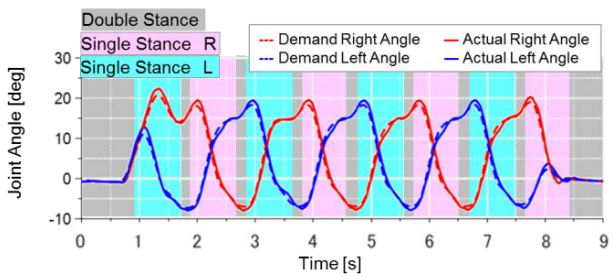

Figure 8: Position time response with proposed interlocking drive system

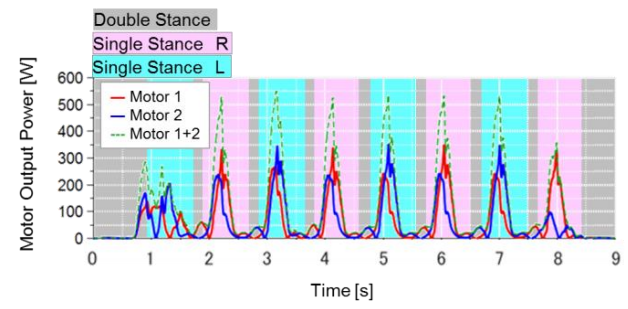

Figure 9: Motor output power without the proposed interlocking drive system

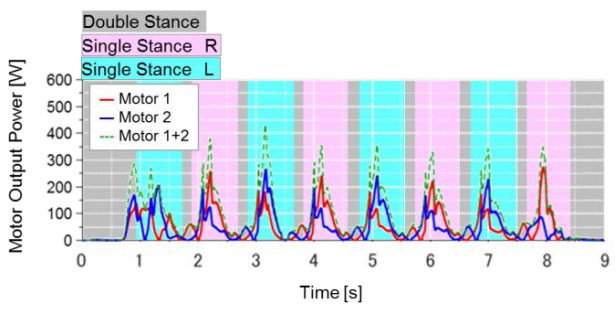

Figure 10: Motor output power with the proposed interlocking drive system

\subsection{Discussion}

It was confirmed that the peak output of the motors in a single stance can be reduced by applying the proposed interlocking drive system. However, as shown in Figure 10, the output of Motor 2 increased in the right stance phase at approximately $8 \mathrm{~s}$. This can be attributed to the fact that the posture of the robot was disturbed at the end of walking. Figure 7 confirms that the upper body was tilted at approximately $7.5 \mathrm{~s}$ due to an error in the joint angle on the swing leg side. Figure 11 shows the results without the use of the interlock drive system reported in the previous study [14]. As shown in Figure 11, when the interlocking system is not used, the error with respect to the target trajectory does not increase during the swinging of the legs. In the interlock system, flow compensation control was proposed 
to control the flow rate of the cylinder on the swing leg side. However, it is surmised that the proposed system could not secure the same accuracy as that of a single HDD system, which directly controls the pump-delivered flow rate due to the valve response and flow control accuracy. This problem can be effectively solved by using a highly responsive valve or improving the flow rate control with a proportional valve.

Thus, it was shown that the proposed interlocking drive system is effective when a high output and a low output are repeated periodically and symmetrically, such as when walking. Figure 12 shows a comparison between the Pump 1 Port A pressures with and without the proposed system in the second step. Figure 13 shows a comparison between the Pump 1 rotation speeds with and without the proposed system in the second step. As shown in Figure 12, the Pump 1 Port A pressure increased from 3.3 MPa to 5.1 $\mathrm{MPa}$ by applying the interlocking system. However, as shown in Figure 13, the Pump 1 rotation speed decreased from $-2826 \mathrm{rev} / \mathrm{min}$ to $-1564 \mathrm{rev} / \mathrm{min}$. Therefore, the Motor 1 output power can be reduced. The pressure increased because the Cylinder 1 rod side was connected to the Cylinder 2 rod side by opening Valve $3 \mathrm{~b}$ in the proposed system. As shown in Figure 14, when the system was switched to the interlocking system after 2.0 $\mathrm{s}$ in the right-stance phase, the cap pressure increased with the rod pressure. As a result, the pump discharge pressure also increased.

In the applied walking pattern, it was necessary for the actuator to actively control the speed, even on the swing leg side. Therefore, for Cylinder 1 without the interlocking system in Figure 14, the Cylinder 1 rod pressure increased during the left-stance phase, which is the swing phase. Applying a walking pattern in which the leg in the swing phase moves passively, as in human walking, is considered to reduce the rod pressure of the cylinder during the swing phase. In such a walking pattern, by reducing the rod pressure of the swing-phase cylinder, the motoroutput reduction effect of the proposed interlocking system will be even higher.

\section{CONCLUSION AND FUTURE WORK}

In this study, performance comparison of a hydraulic interlocking drive system with a conventional HDD was conducted to verify the energy reduction effect. A hydraulic and mechanical co-simulation model was used for the evaluation. The results of the simulations confirmed that walking along a predetermined path was possible with the proposed system, and the simulation model was thus tuned based on the experimental results. The results also showed that the motor output could be reduced by $24.3 \%$ for walking motion and that the proposed system contributes to size reduction of the installed motors for biped humanoid robots.

In the future, it will be necessary to improve flow control accuracy for flow compensation of the interlock drive system. The proposed system will be applied to a biped humanoid robot to conduct a walking experiment.

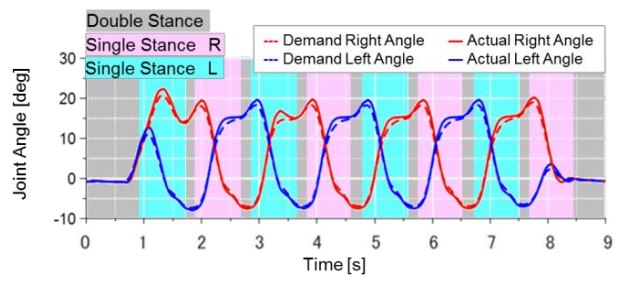

Figure 11: Position time response without the proposed interlocking drive system

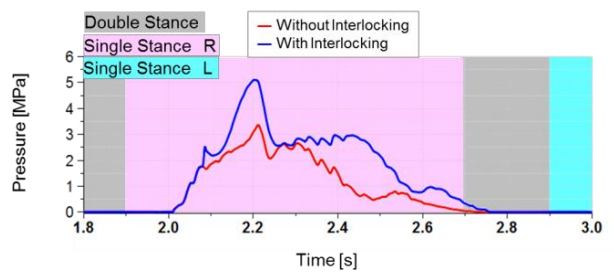

Figure 12: Pressure of Pump 1 Port A

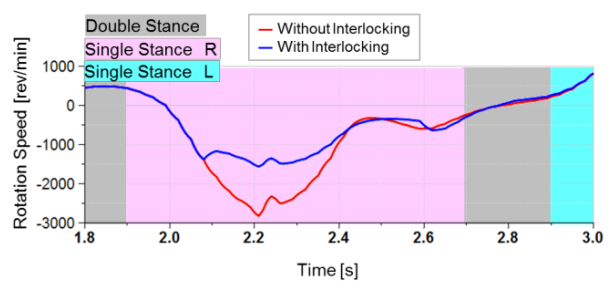

Figure 13: Rotation speed of Pump 1 


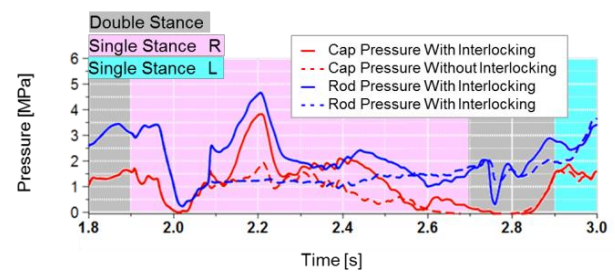

Figure 14: Pressure of Cylinder 1

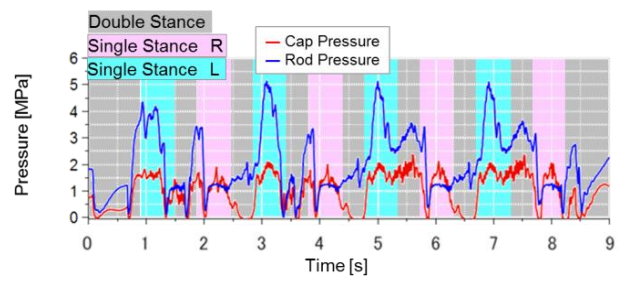

Figure 15: Pressure of Cylinder 1 without the proposed interlocking drive system

\section{ACKNOWLEDGMENT}

This study was conducted with the support of the Research Institute for Science and Engineering of Waseda University and the Future Robotics Organization of Waseda University. This study was part of the humanoid project at the Humanoid Robotics Institute of Waseda University. We would like to thank Editage (www.editage.jp) for English language editing.

\section{NOMENCLATURE}

$H D D \quad$ Hydraulic direct-drive system

$Q \quad$ Flow rate

A Area

$\omega \quad$ Rotational speed

D Displacement

$\eta \quad$ Efficiency

$P \quad$ Pressure

$\rho \quad$ Density

\section{REFERENCES}

[1] Ogura Y, Shimomura K, Kondo H, Morishima A, Okubo T, Momoki S, Lim HO, Takanishi A (2006) Human-like Walking with Knee Stretched, Heel-Contact and Toe-Off Motion by a Humanoid Robot in the 2006 IEEE/RSJ Int Conf on Intelligent Robots and Systems 39763981

[2] Otani T, Hashimoto K, Hamamoto S, Miyamae S, Sakaguchi M, Kawakami Y, Lim HO,
Takanishi A (2015) Knee Joint Mechanism that Mimics Elastic Characteristics and Bending in Human Running in the 2015 IEEE/RSJ Int Conf on Intelligent Robots and Systems 51565161

[3] Otani T, Hashimoto K, Miyamae S, Ueta H, Sakaguchi M, Kawakami Y, Lim HO, Takanishi A (2017) Angular Momentum Compensation in Yaw Direction Using Upper Body Based on Human Running in the 2017 IEEE Int Conf on Robotics and Automation 4768-4775

[4] Urata J, Nakanishi Y, Okuda K, Inaba M (2010) Design of High Torque and High Speed Leg Module for High Power Humanoid in the 2010 IEEE/RSJ Int Conf on Intelligent Robots and Systems 4497-4502.

[5] Ito Y, Nozawa S, Urata J, Nkaoka T, Kobayashi K, Nakanishi Y, Okada K, Inaba M (2014) Development and Verification of Life-Size Humanoid with High-Output Actuation System in the 2014 IEEE Int Conf on Robotics and Automation 3433-3438.

[6] Park I, Kim J, Lee J, Oh J (2007) Mechanical Design of the Humanoid Robot Platform, HUBO. Advanced Robotics 21(11) 1305-1322

[7] Kaneko K, Kaminaga H, Sakaguchi T, Kajita S, Morisawa M, Kumagai I, Kanehiro F (2019) Humanoid Robot HRP-5P: An Electrically Actuated Humanoid Robot with High Power and Wide Range Joints. IEEE Robotics and Automation Letters 4(2) 1431-1438

[8] Atlas Boston Dynamics,

https://www.bostondynamics.com/atlas, accessed 2019/11/12.

[9] Hyon S, Suewaka D, Torii Y, Oku N (2017) Design and Experimental Evaluation of a Fast Torque-Controlled Hydraulic Humanoid Robot. IEEE/ASME Transactions on Mechatronics 22(2) 623-634

[10] Rahmfeld R, Ivantysynova M (1998) Energy Saving Hydraulic Actuators for Mobile Machines in the First Bratislavian Fluid Power Symp 47-57.

[11] Zimmerman J, Busquets R, Ivantysynova M (2011) 40\% Fuel Savings by Displacement Control Leads to Lower Working Temperatures - A Simulation Study and Measurements in the Fifty-Second Nat Conf on Fluid Power 693701 .

[12] Kaminaga H, Ono J, Nakashima Y, Nakamura Y (2009) Development of Backdrivable Hydraulic Joint Mechanism for Knee Joint of 
Humanoid Robots in the 2009 IEEE Int Conf on Robotics and Automation 1577-1582.

[13] Shimizu J, Otani T, Mizukami H, Hashimoto K, Takanishi A (2019) Experimental Validation of High-Efficiency Hydraulic Direct-Drive System for a Biped Humanoid Robot in the 2019 IEEE Int Conf. on Robotics and Automation 9453-9458.

[14] Shimizu J, Otani T, Hashimoto K, Takanishi A (2019) Simulation of a Hydraulic Direct-Drive System for a Biped Walking Robot in the 16th Scandinavian Int Conf on Fluid Power B6.1.

[15] Shimizu J, Otani T, Mizukami H, Hashimoto K, Takanishi A (2019) Experimental Validation of Hydraulic Interlocking Drive System for Biped Humanoid Robot in the 2019 IEEE/RSJ Int Conf on Intelligent Robots and Systems 71637169.

[16] Takako Industries, INC., http://www.takakoinc.com/, accessed 2019/11/12. 